\title{
РОЛЬ ПОЛИМОРФИЗМА (rs55754655) ГЕНА ФЕРМЕНТА АНТИОКСИДАНТНОЙ СИСТЕМЫ В РАЗВИТИИ ХРОНИЧЕСКОГО ПАНКРЕАТИТА
}

\author{
(С Самгина Т.А. ${ }^{1}$, Канищев Ю.В. ${ }^{3}$, Аль Исаи Ханан С.А. ${ }^{l}$, Назаренко П.М. ${ }^{1}$, Полоников А.В. ${ }^{2}$ \\ ${ }^{1}$ Кафедра хирургических болезней № 2 , \\ ${ }^{2}$ кафедра биологии, медицинской генетики и экологии, ${ }^{3}$ кафедра хирургических болезней ФПО \\ Курского государственного медицинского университета, Курск
}

E-mail: tass@list.ru

\begin{abstract}
Важная роль в развитии хронического панкреатита (ХП) отводится действию токсических веществ и нарушению регуляции процессов про- и антиоксидантной защиты. Одним из прооксидантных ферментов является альдегидоксидаза $(A O X 1)$, которая играет ключевую роль в метаболизме ксенобиотиков. Цель исследования - изучение связи полиморфизма (rs55754655) гена $A O X 1$ с развитием ХП в русской популяции. Образцы цельной крови были собраны у 241 больного ХП и 132 здоровых индивидов. Генотипирование полиморфизма (rs55754655) гена $A O X 1$ выполнено с помощью метода ПЦР с дискриминацией аллелей с помощью ТаqMan-зондов. Обнаружено, что носительство аллеля G $(\mathrm{OR}=2.49$ 95\% CI 1.27-4.88 p=0.01) и генотипа $\mathrm{A} / \mathrm{G}$ ассоциировалось с повышенным риском развития XП (OR=2.8 95\% CI 1.32-5.86 p=0.01). Проведенный стратифицированный анализ по полу показал, что генотип A/G aсcоциирован с развитием ХП только у женщин $(\mathrm{OR}=2.57$ 95\% CI 1.09-6.04 p=0.01). Курящие пациенты с генотипом А/G имеют высокий риск развития ХП (OR $=6.4795 \% \mathrm{CI} 0.82-51.23, \mathrm{p}=0.05)$.
\end{abstract}

Ключевые слова: хронический панкреатит, полиморфизм rs55754655 гена альдегидоксидазы.

\section{ROLE OF THE POLYMORPHISM (rs55754655) OF THE ENZYME GENE OF THE ANTIOXIDANT SYSTEM IN THE DEVELOPMENT OF CHRONIC PANCREATITIS Samghina T.A. ${ }^{l}$, Kanishchev Y.V. ${ }^{3}$, Al Isaee Hanan S.A. ${ }^{l}$, Nazarenko P.M. ${ }^{l}$, Polonikov A.V. ${ }^{2}$ \\ ${ }^{1}$ Department of Surgical Diseases N 2, ${ }^{2}$ Department of Biology, Medical Genetics and Ecology; \\ ${ }^{3}$ Department of Surgical Diseases of FPE of Kursk State Medical University, Kursk}

An important role in the development of chronic pancreatitis (CP) is given to the action of toxic substances and the disruption of the regulation of pro- and antioxidant defense processes. One of the prooxidant enzymes is aldehyde oxidase (AOX1), which plays a key role in the metabolism of xenobiotics. The aim of the study was to study the relationship between the polymorphism (rs55754655) of the AOX1 gene and the development of CP in the Russian population. Whole blood samples were collected from 241 patients with CP and 132 healthy individuals. Genotyping of the polymorphism (rs55754655) of the AOX1 gene was performed using the PCR method with discrimination of alleles with the help of TaqMan probes. It was found that the carriage of the $\mathrm{G}$ allele $(\mathrm{OR}=2.4995 \% \mathrm{CI} 1.27-4.88 \mathrm{p}=0.01)$ and the $\mathrm{A} / \mathrm{G}$ genotype was associated with an increased risk of developing $\mathrm{CP}(\mathrm{OR}=2.895 \% \mathrm{CI} 1.32-5.86 \mathrm{p}=0.01)$. The stratified gender analysis showed that the genotype $\mathrm{A} / \mathrm{G}$ was associated with the development of CP only in women $(\mathrm{OR}=2.5795 \% \mathrm{CI} 1.09-6.04 \mathrm{p}=0.01)$. Smokers with $\mathrm{A} / \mathrm{G}$ genotype have a high risk of developing chronic pancreatitis $(\mathrm{OR}=6.4795 \%$ CI $0.82-51.23, \mathrm{p}=0.05)$.

Keywords: chronic pancreatitis, polymorphism rs55754655 of the aldehyde oxidase gene.

Хронический панкреатит (ХП) - хроническое рецидивирующее воспалительное заболевание поджелудочной железы (ПЖ), приводящее к прогрессирующей атрофии железистой ткани органа, замещению соединительной тканью клеточных элементов паренхимы, поражению протоков, болевому синдрому и потере экзо- и эндокринной функций железы. Ведущей причиной развития тяжелых изменений паренхимы ПЖ при ХП считают генные мутации, среди которых основную роль отводят нарушениям в генах трипсиногена и ингибитора протеазы серина (PRSS1 и SPINK1). Наследование этих генетических дефектов может проявляться уже в детском возрасте [2, 7]. Важная роль в развитии панкреатита отводится цитотоксическому действию свободных радикалов, повышенная генерация которых происходит вследствие нарушения регуляции процессов про- и ан- тиоксидантной защиты, контролирующихся ферментами редокс-гомеостаза [1]. Одним из прооксидантных ферментов является альдегидоксидаза $(A O X 1)$, которая играет ключевую роль в метаболизме ксенобиотиков и лекарственных средств, содержащих ароматические азагетероциклические заместители. Фермент является представителем молибдофлавоэнзимов и участвует в процессе окисления альдегидов в соответствующие карбоновые кислоты, а также пуринов, витаминов, различных токсических веществ и фармакологических препаратов, в том числе и ацетальдегида токсического продукта распада этанола [6]. Тот факт, что фермент экспрессируется в достаточно большом количестве в клетках поджелудочной железы, свидетельствует о его потенциальной вовлеченности в важнейшие физиологические и патологические процессы в данном органе. При- 
мечательно, что один из субстратов $A O X 1$ является иммунодепрессант азатиоприн - лекарственный препарат, способный провоцировать развитие острого панкреатита [3, 12].

По всей видимости, $A O X 1$ вовлечен в метаболизм, имеющий важное патогенетическое значение для развития панкреатита. До настоящего времени ген альдегидоксидазы не рассматривался в качестве возможного кандидата предрасположенности к хроническому панкреатиту, хотя патогенетическая значимость гена $A O X 1$ в отношении заболевания представляется возможной.

Цель настоящего исследования - изучение ассоциации частого полиморфизма (rs55754655) гена $A O X 1$ с риском развития хронического панкреатита у жителей Курской области. Выбор данного гена для исследования был обусловлен, во-первых, его достаточно высокой экспрессией в тканях поджелудочной железы, что указывает на его важную биологическую роль в метаболизме органа, вовторых, вовлеченностью в окисление широкого спектра эндо- и экзогенных альдегидов и панкреотоксического препарата азатиоприна и, в-третьих, потенциальным участием фермента в детоксикации реактивных форм кислорода, обладающих повреждающим действием на органы и ткани [4]. Полиморфизм (rs55754655) представляет собой миссенсмутацию Asn1135Ser, которая может оказывать влияние на активность фермента.

\section{МАТЕРИАЛЫ И МЕТОДЫ ИССЛЕДОВАНИЯ}

Материалом для исследования послужили образцы ДНК, полученные от 241 неродственного больного хроническим панкреатитом (191 женщина и 50 мужчин), находившихся на стационарном лечении в хирургических отделениях городской больницы № 4 и областной клинической больницы на ст. Курск в период с 2012 по 2015 год, и 132 неродственных индивидов русской национальности без заболеваний ЖКТ (93 женщины и 39 мужчин). Контрольная группа формировалась в ходе профилактических осмотров на предприятиях и государственных учреждениях, а также в стационарах ЛПУ г. Курска. Средний возраст больных составил 56,9+12,2, здоровых лиц - 56,8+12,5. Диагноз ХП устанавливался в соответствии с Национальными клиническими рекомендациями с использованием общеклинических, лабораторных (общий и биохимический анализ крови) и инструментальных (УЗИ и МРТ поджелудочной железы, ЭФГДС) методов исследования [http: // обществохирургов. pф/stranica-pravlenija/unkr/].

Проводилось анкетирование пациентов по курению, объему, частоте и длительности употреб- ления алкогольных напитков, с последующим перерасчетом в граммы этанола и формированием в группы: курящие и некурящие, употребляющие менее и $\geq 200$ г этанола в неделю, пьющие реже и $\geq 1$ дней в неделю, в зависимости от длительности употребления алкоголя: до 10 лет, $\geq 10$ лет [5].

У всех обследуемых проводился забор венозной крови для проведения молекулярногенетического анализа и биохимических исследований. Геномную ДНК выделяли стандартным методом фенольно-хлороформной экстракции. Генотипирование полиморфизма (rs55754655) гена $A O X 1$ проводилось методом ПЦР в режиме реального времени путем дискриминации аллелей с помощью TaqMan-зондов на амплификаторе CFX96 (Bio-Rad Laboratories, США) с использованием коммерческих наборов реактивов TaqMan SNP Genotyping Assays фирмы Applied Biosystems (США). Контроль качества генотипирования 10\% исследованных образцов, отобранных по случайному принципу и при отсутствии информации о статусе болезни, показал 100\% совпадение с первоначальными данными генотипирования. Для оценки ассоциаций аллелей и генотипов гена $A O X 1$ с риском развития ХП использовали критерий $\chi^{2}$ и отношение шансов (OR) с $95 \%$ доверительными интервалами (CI). Статистический анализ осуществлялся с использованием программы Statistica 6.0 ("StatSoft", США).

\section{РЕЗУЛЬТАТЫ ИССЛЕДОВАНИЯ И ИХ ОБСУЖДЕНИЕ}

Частоты аллелей и генотипов полиморфизма (rs55754655) гена $A O X 1$ представлены в таблице 1. Генотипы исследуемого полиморфизма находились в соответствии с распределением Харди-Вайнберга в обеих исследованных группах $(\mathrm{p}>0,05)$. Как видно из таблицы 1 , носительство аллеля $\mathrm{G}(\mathrm{OR}=2.49$ 95\% CI 1.27-4.88 p=0.01) и генотипа $\mathrm{A} / \mathrm{G}$ ассоциировалось с повышенным риском развития хронического панкреатита $(\mathrm{OR}=2.895 \%$ CI 1.32-5.86 p=0.01).

Проведенный стратифицированный анализ по полу (таблица 2) показал, что генотип A/G был ассоциирован с развитием хронического панкреатита только у женщин ( $\mathrm{OR}=2.57$ 95\% CI 1.09-6.04 $\mathrm{p}=0.01$ ).

Затем мы проанализировали совместное влияние генотипов изучаемого полиморфизма и факторов риска ХП (курение, частота, объем и длительность употребления алкогольных напитков) на развитие заболевания. Было обнаружено, что курящие пациенты с генотипом A/G имеют высокий риск развития хронического панкреатита $(\mathrm{OR}=6.47$ 95\%CI 0.82-51.23, $\mathrm{p}=0.05)$. 
Частоты аллелей и генотипов полиморфизма (rs55754655) гена $A O X 1$

в группах, больных хроническим панкреатитом, и здоровых лиц

\begin{tabular}{|c|c|c|c|c|c|c|}
\hline \multirow{2}{*}{$\begin{array}{c}\text { Генотипы / } \\
\text { аллели }\end{array}$} & \multicolumn{2}{|c|}{ Больные ХП } & \multicolumn{2}{|c|}{ Здоровые лица } & \multirow{2}{*}{$\chi^{2}(p)$} & \multirow{2}{*}{ OR $(95 \% \mathrm{CI})$} \\
\hline & $\mathrm{n}$ & $\%$ & $\mathrm{n}$ & $\%$ & & \\
\hline \multicolumn{7}{|c|}{ Сравнение групп больных ХП (n=241) и здоровых лиц (n=132) } \\
\hline $\mathrm{A} / \mathrm{A}$ & 197 & 81,7 & 122 & 92,4 & - & - \\
\hline $\mathrm{A} / \mathrm{G}$ & 41 & 17,0 & 9 & 6,8 & 7,64 (0.01) & $2,8(1,32-5,86)$ \\
\hline $\mathrm{G} / \mathrm{G}$ & 3 & 1,2 & 1 & 0,8 & $0,19(0,66)$ & $1,65(0,17-16,04)$ \\
\hline $\mathrm{A}$ & \multicolumn{2}{|c|}{0,902} & \multicolumn{2}{|c|}{0,958} & \multirow{2}{*}{$7,42(0,01)$} & \multirow{2}{*}{$2,49(1,27-4,88)$} \\
\hline G & & & & & & \\
\hline
\end{tabular}

Таблица 2

Частоты аллелей и генотипов полиморфизма (rs55754655) гена $A O X 1$ среди женщин и мужчин, больных хроническим панкреатитом, и здоровых лиц

\begin{tabular}{|c|c|c|c|c|c|c|}
\hline \multirow{2}{*}{$\begin{array}{c}\text { Генотипы / } \\
\text { аллели }\end{array}$} & \multicolumn{2}{|c|}{ Больные ХП } & \multicolumn{2}{|c|}{ Здоровые лица } & \multirow{2}{*}{$\chi^{2}(p)$} & \multirow{2}{*}{ OR $(95 \% \mathrm{CI})$} \\
\hline & $\mathrm{n}$ & $\%$ & $\mathrm{n}$ & $\%$ & & \\
\hline \multicolumn{7}{|c|}{ Сравнение групп больных ХП (n=191) и здоровых лиц (n=93)среди женщин } \\
\hline $\mathrm{A} / \mathrm{A}$ & 156 & 81,7 & 85 & 91,4 & - & - \\
\hline $\mathrm{A} / \mathrm{G}$ & 33 & 17,3 & 7 & 7,5 & $4,91(0,03)$ & $2,57(1,09-6,04)$ \\
\hline $\mathrm{G} / \mathrm{G}$ & 2 & 1,0 & 1 & 1,1 & & \\
\hline $\mathrm{A}$ & \multicolumn{2}{|c|}{0,903} & \multicolumn{2}{|c|}{0,952} & \multirow{2}{*}{$3,95(0,05)$} & \multirow{2}{*}{$2,11(1,0-4,47)$} \\
\hline G & \multicolumn{2}{|c|}{0,097} & & & & \\
\hline \multicolumn{7}{|c|}{ Сравнение групп больных ХП (n=50) и здоровых лиц $(\mathrm{n}=39)$ среди мужчин } \\
\hline $\mathrm{A} / \mathrm{A}$ & 41 & 82,0 & 37 & 94,9 & $3,35(0,07)$ & $4,06(0,82-20,02)$ \\
\hline $\mathrm{A} / \mathrm{G}$ & 8 & 16,0 & 2 & 5,1 & $2,60(0,11)$ & $3,52(0,70-17,65)$ \\
\hline $\mathrm{G} / \mathrm{G}$ & 1 & 2,0 & 0 & 0 & $0,79(0,37)$ & - \\
\hline $\mathrm{A}$ & \multicolumn{2}{|c|}{0,900} & \multicolumn{2}{|c|}{0,974} & \multirow{2}{*}{$3,85(0,05)$} & \multirow{2}{*}{$4,22(0,9-19,87)$} \\
\hline $\mathrm{G}$ & \multicolumn{2}{|c|}{0,100} & \multicolumn{2}{|c|}{0,026} & & \\
\hline
\end{tabular}

В рамках настоящего исследования впервые выявлена ассоциация полиморфизма (rs55754655) гена $A O X 1$ с повышенным риском развития хронического панкреатита. Стратифицированный анализ по полу показал, что генотип $\mathrm{A} / \mathrm{G}$ был ассоциирован с развитием хронического панкреатита только у женщин. Также было обнаружено, что курящие пациенты с генотипом A/G имеют высокий риск развития хронического панкреатита.

Изучению полиморфизмов гена $A O X 1$ посвящено небольшое количество исследований. В частности полиморфизм (rs55754655) гена $A O X 1$ изучался у 156 пациентов, перенесших трансплантацию почки и получавших в послеоперационном периоде азатиоприн [9]. Авторы исследования обнаружили, что пациенты носители вариантного генотипа $\mathrm{G} / \mathrm{G}$ нуждаются в более высоких дозах азатиоприна, что косвенно свидетельствует об увеличенной активности фермента в отношении метаболизма лекарственного препарата у носителей данного генетического варианта. Дополнительным подтверждением данного факта стали результаты другого исследования, в котором обнаружено отсутствие эффекта от лечения стандартными дозами азатиоприна пациентов с воспалительными заболеваниями кишечника у носителей вариантного генотипа $A O X 1$ [11].

В литературе опубликованы результаты функционального исследования полиморфизмов гена $A O X 1$, было показано, что нуклеотидная замена сопровождается аминокислотной заменой Asn на Ser в 1135 положении полипептида (Asn1135Ser или 3404AG), которая расположена близко к домену димеризации и может оказывать влияние на стабильность фермента [8]. Вариантный генотип (1135AsnSer или 3404AG) связан с увеличением активности фермента за счет повышения его стабильности [8]. Можно предположить, что повышенная активность фермента у носителей генотипа 3404AG может способствовать усиленной генерации супероксидного анионного радикала, развитию окислительного стресса, повреждению митохондрий и таким образом способствовать запуску каскада деструктивных изменений в поджелудочной железе, вызванных высвобождением пищеварительных ферментов. Подобный механизм развития острого панкреатита предполагается на фоне лечения азатиоприном [12]. В то же самое время ассоциация генотипа 3404AG с повышенным риском разви- 
тия ХП нами обнаружена только у женщин. Из литературы известен факт, что активность альдегидоксидазы может ингибироваться под влиянием женского полового гормона эстрадиола [10], что противоречит нашему суждению о связи повышенной активности фермента и развитием болезни. Однако можно сделать предварительный вывод о том, что ген $A O X 1$ можно рассматривать в качестве нового кандидатного гена предрасположенности к хроническому панкреатиту.

Следует продолжить дальнейшее исследование по оценке вовлеченности других полиморфизмов гена $A O X 1$ в развитие хронического панкреатита. В случае независимого подтверждения выявленной в нашей работе ассоциации в других популяциях мира, данный маркер может претендовать на роль потенциальной мишени для генетического тестирования наследственной предрасположенности к хроническому панкреатиту с целью выявления формирования среди населения группы повышенного риска развития болезни.

\section{ЛИТЕРАТУРА}

1. Баранов В.С., Баранова Е.В., Иващченко Т.Е. Геном человека и гены предрасположености. Введение в предиктивную медицину. - СПб. : Интермедика, 2000. $-272 \mathrm{c}$.

2. Нестеренко Ю.А., Шаповальянц С.Г., Зубков О.Б. Морфологические аспекты в хирургии хронического панкреатита // Хирургия. Журнал им. Н.И. Пирогова. - 1993. - № 10. - С. 19-24.

3. Floyd A., Pedersen L., Nielsen G.L., Ole ThorlaciusUssing, Sorensen H.T. Risk of acute pancreatitis in users of azathioprine: a population-based case-control study // Am. J. Gastroenterol. - 2003. - Vol. 98, N 6. - P. 1305-1308. - doi: 10.1016/S00029270(03)00233-8.

4. Fu C., Di L., Han X., Soderstrom C., Snyder M., Troutman M.D., Obach R., Zhang H. Aldehyde oxidase 1 (AOX1) in human liver cytosols: quantitative characterization of AOX1 expression level and activi- ty relationship // Drug. Metab. Dispos. - 2013. Vol. 41, N 10. - P. 1797-1804. - doi: 10.1124/dmd.113.053082.

5. Furtwaengler N.A., de Visser R.O. Lack of international consensus in low-risk drinking guidelines // Drug. Alcohol. Rev. - 2013. - Vol. 32, N 1. P. 11-18. - doi: 10.1111/j.1465-3362.2012.00475.x.

6. Garattini E., Fratelli M., Terao M. The mammalian aldehyde oxidase gene family // Hum Genomics. 2009. - Vol. 4, N 2. - P.119-130.

7. Goh K.L. Chronic pancreatitis: aetiology, epidemiology and clinical presentation // Med. J. Malaysia. - 2005. - Vol. 60, Suppl B. - P. 94-98.

8. Hartmann T., Terao M., Garattini E., Teutloff C., Alfaro J.F., Jones J.P., Leimkühler S. The impact of single nucleotide polymorphisms on human aldehyde oxidase // Drug Metab Dispos. - 2012. - Vol. 40, N 5. P. 856-864. - doi: 10.1124/dmd.111.043828.

9. Kurzawski M., Dziewanowski K., Safranow K., Drozdzik $M$. Polymorphism of genes involved in purine metabolism (XDH, AOX1, MOCOS) in kidney transplant recipients receiving azathioprine // Ther Drug Monit. - 2012. - Vol. 34, N 3. - P. 266-274. doi: 10.1097/FTD.0b013e31824aa681.

10. Obach R.S., Huynh P., Allen M.C., Beedham C. Human liver aldehyde oxidase: inhibition by 239 drugs // J Clin Pharmacol. - 2004. - Vol. 44, N 1. - P. 7-19. doi: 10.1177/0091270003260336

11. Smith M.A., Marinaki A.M., Arenas M., ShobowaleBakre M., Lewis C.M., Ansari A., Duley J., Sanderson J.D. Novel pharmacogenetic markers for treatment outcome in azathioprine-treated inflammatory bowel disease // Aliment Pharmacol Ther. - 2009. Vol. 30, N 4. - P. 375-384. - doi: 10.1111/j.13652036.2009.04057.x.

12. Teich N., Mohl W., Bokemeyer B., Bündgens B., Büning J., Miehlke S., Hüppe D., Maaser C., Klugmann T., Kruis W., Siegmund B., Helwig U., Weismüller J., Drabik A., Stallmach A.; German IBD Study Group. Azathioprine-induced Acute Pancreatitis in Patients with Inflammatory Bowel Diseases--A Prospective Study on Incidence and Severity // J Crohns Colitis. - 2016. - Vol. 10, N 1. - P. 61-68. - doi: 10.1093/ecco-jcc/jjv188. 